\title{
Cystatin-C in patients with acute coronary syndrome: Correlation with ventricular dysfunction, and affected coronary vessels
}

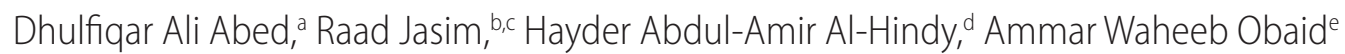

aDepartment of Medicinal Chemistry, College of Pharmacy, University of Babylon, Babylon, Iraq.

bPharmacology and Therapeutics, Monash Institute of Pharmaceutical Sciences, Faculty of Pharmacy and Pharmaceutical Sciences, Monash University, Clayton, Australia.

'Department Pharmacology and Therapeutics, College of Pharmacy, University of Babylon, Babylon, Iraq.

dPharmacology \& toxicology Department, College of Pharmacy, University of Babylon, Babylon, Iraq.

eF.I.M.S (Path.)

Correspondence to: Hayder Abdul-Amir Makki Al-Hindy (email: makihayder68@gmail.com).

https://orcid.org/0000-0001-6232-8501,

(Submitted: 03 November 2019 - Revised version received: 14 December 2019 - Accepted: 22 January 2020 - Published online: 26 February 2020)

\begin{abstract}
Objective This study is designed to inspect the circulating levels of cystatin C (Cy/C) in patients with acute coronary syndrome (ACS) and to evaluate the association of Cy/C levels with ejection fraction and angiographic number of stenosed coronaries.

Methods 136 participants with ACS were enrolled in this case-control survey and compared with 94 control. Hematological assessments were done for all the participants and included $C y / C$, creatinine, and uric acid were measured using conventional techniques. Creatinine clearance rate was calculated and estimated glomerular-filtration-rate (eGFR) were measured. Echocardiographic assessment of ejection fraction was done with a cut-off point $<40$ left ventricular ejection fraction\% designated for LV systolic dysfunction. Angiographic evaluation involved in this study depending on the severity of stenosed coronaries by calculating number of arteries display not less than 1 critical stenosis (designed as $>70 \%$ decrease in caliber).

Results Ejection fraction was significantly lower in in ACS patients than control group $(p<0.05)$. Serum Cy/C was significantly higher in patients' group. The mean plasma uric acids values were significantly higher in patients' group $(p-0.001)$ but with no significant differences in creatinine and creatinine clearance $(p<0.05)$ observed between groups. The eGFR were significantly lower in ACS people compared to healthy persons. Correlation studies of $\mathrm{Cy} / \mathrm{C}$ showed positive correlation with serum creatinine and serum uric acid; as well as nonsignificant negative correlation with eGFR ( $p>0.05)$.

Conclusion Besides the role of $\mathrm{Cy} / \mathrm{C}$ in early detection of renal dysfunction, it could have a role in diagnosis of ACS and evaluation of LV systolic dysfunction. Nevertheless, this study showed Cy/C was not related to the number of coronary arteries affected.

Keywords cystatin C, acute coronary syndrome, left ventricular ejection fraction, coronary angiography.
\end{abstract}

\section{Introduction}

Cystatin- $\mathrm{C}(\mathrm{Cy} / \mathrm{C})$ is an innovative biomarker of renal function, which seems to share even strong correlation with mortality and vascular risk over serum creatinine or estimated-glomerular filtration rate (eGFR) in aging and admitted acute coronary syndrome (ACS) subjects. Whether a high risk of coronary-vascular diseases related to elevated $\mathrm{CyC}$ is due to amplified ischemic load, raised risk of embolism, or another pathway is uncertain. $.^{1-3} \mathrm{Cy} / \mathrm{C}$ is formed and released by cardiac cells, where its production is raised up during myocardial necrosis.

Three clinical subtypes of ACS, involving unstable angina, and ST and non-ST segment elevation myocardial infarction (MI), are primary causes of mortality and debility universally. ${ }^{2}$ The incremental role of $\mathrm{Cy} / \mathrm{C}$ beyond conventional renal and cardiac markers leftovers moderately discovered. ${ }^{4} \mathrm{Cy} / \mathrm{C}$ is not influenced by age, sex, race, and lean body mass and may be more suitable for sensing mild-moderate changes in eGFR. ${ }^{5}$ A closer look at the recent data indicates that higher values of $\mathrm{Cy} / \mathrm{C}$ in patients with $\mathrm{ACS}$ are associated with raised risk for cardiovascular events and death independent of renal function. ${ }^{6}$

This study is designed to inspect the circulating levels of $\mathrm{Cy} / \mathrm{C}$ in patients with ACS and to evaluate the association of $\mathrm{Cy} / \mathrm{C}$ levels with ejection fraction and an angiographic number of stenosed coronaries.

\section{Materials and Methods}

This is a single-center study, patients were recruited from Shahid al-Mihrab Center for interventional cardiology; all had prearranged admission for diagnostic or therapeutic catheterization.

\section{Study Participants}

Patients were diagnosed as pure ACS $(n=136)$ only without other cardiac pathologies by a cardiologist and referred for further interventional catheterization. Sex and age wellmatched healthy controls $(n=94)$ were selected as being free of any cardiological disabilities or any renal impairment. Body mass index (BMI), smoking habits, and history of diabetes mellitus and hypertension were also included in the study.

\section{Description of ACS}

Entire ACS patients met the diagnostic standards established by the 2014 American Heart Association (AHA)/American College of Cardiology (ACC) guidelines for managing non-STsegment elevation ACSs and the 2013 ACC Foundation/AHA guideline for the management of ST-segment elevation MI.

\section{Quartiles of Cystatin-C in Study Subjects}

We classified ACS patients into quartiles based on their blood Cy/C levels; $<0.9,0.9-1.49,1.5-1.99$, and $>2.0 \mathrm{mg} / \mathrm{L} .{ }^{1}$ The 
study population was stratified according to their levels of serum uric acid (SUA) at their first 6-12 h of admission, into two groups: first $(<6.3 \mathrm{mg} / \mathrm{dL})$, second $(\geq 6.3 \mathrm{mg} / \mathrm{dL})$.

\section{Measurements of Other Biochemical Assays}

All hematological assays were performed on the day of presentation on fasting blood which was drawn and stored at minus $70^{\circ} \mathrm{C}$. Cy/C was measured by using Elabscience Human $\mathrm{Cy} / \mathrm{C}$ ELISA kit. While both creatinine and UA were measured using a conventional techniques. The creatinine clearance rate calculated using the Cockcroft-Gault formula in $\mathrm{mL} / \mathrm{min}$ from plasma creatinine measured by $\mathrm{mol} / \mathrm{L}$ as follows: ${ }^{7}$

\section{Creatinine Clearance $=\{(140-$ Age $) x w t(k g) x F\} /($ Serum Creatinine $\left.{ }^{\star} 0.8136\right)$ where $F=1$ for men, and 0.85 for women}

eGFR was measured by means of a new evaluation method established by adjusting of "Modification-of-Diet-in-RenalDisease Study" formula, depending on information from "Chinese CKD" subjects: ${ }^{8}$

\section{eGFR $(\mathrm{ml} / \mathrm{min}$ per $1.73 \mathrm{~m} 2)=175 \times S c r^{-1.234} \times \operatorname{age}^{-0.179}$; $[S c r-m g / d l . . . . . . a n d ~ i f f e m a l e ~ \times 0.742$}

25 subjects who had renal impairment defined as an eGFR $<60$, were omitted.

\section{Echocardiographic Study}

Standard echocardiographic examination was done at rest by means of a VIVID 9 apparatus (GE Healthcare ${ }^{\circledR}$ ) with 2.5/3.5$\mathrm{MHz}$ probe. A single qualified physician performed echocardiography. The left ventricular ejection fraction (LVEF\%) measured by using "modified Simpson's technique". A cut-off point $<40 \mathrm{LVEF} \%$ designated for expressing LV systolic dysfunction. Henceforth, ACS patients divided into two-subgroups: $\mathrm{EF}<40 \%$ vis $\geq 40 \%{ }^{9}$

\section{Coronary Angiography}

At least, two-skillful angiographers inspected angiography images, whereas severity of stenosed coronaries evaluated by calculating number of arteries displays not $<1$ critical stenosis (designed as $>70 \%$ decrease in caliber).

\section{Biostatistics Assay}

All statistics finalized with SPSS software, version 25. The ACS patients were clustered into quartiles based on their serum $\mathrm{Cy} / \mathrm{C}$ levels. ANOVA was used for continuous covariates and chi-square for dichotomous variables. Comparisons of continuous data (given as means) were performed by means of $t$-tests for independent samples. Receiver operating characteristic (ROC) curve studies were performed to establish specificity/ sensitivity. Univariate logistic regression analysis was done wherever required.

\section{Ethical Consideration}

A conversant consent at the commencement obtained from each participant (or family associate) for ACS subjects and controls individually, and our study final approval from the local committee for research ethics at University of Babylon. Arranged authorization for blood sampling, besides hospital approval by ethical committee of the entire work.

\section{Results}

Mean age of our ACS patients was $59.3 \pm 13.1$ years, which is not unlike the age of the control group. Similarly, BMI did not significantly differ between the two study groups. The males' number was $92(67.7 \%)$, which were less significant than the control 83 (88.29\%). The mean LVEF\% was incomparable between the groups being lower in the ACS group, even though, the mean EF\% of both study groups still were within the normal limits. The mean levels of creatinine and calculated creatinine clearance for ACS and control subjects were parallels mutually. The mean plasma UA values were significantly higher in the patients $(p-0.001)$. Correspondingly, the estimated GFR was significantly lower in ACS people compared to healthy persons (109.6-127 ml/min per $1.73 \mathrm{~m}^{2}$ ), sequentially. A higher incidence of risk-factors in terms of concomitant hypertension and diabetes in ACS patients were significant $(p-0.05)$. Serum Cy/C levels were significantly higher in cardiac patients (Table 1).

\begin{tabular}{|c|c|c|c|c|c|}
\hline Characteristics & Group & Number & Mean & $\begin{array}{l}\text { Std. } \\
\text { deviation }\end{array}$ & $P$-value \\
\hline \multirow{2}{*}{ Age } & 1 & 136 & 59.3 & 13.1 & \multirow{2}{*}{$>0.05$} \\
\hline & 2 & 94 & 51.9 & 12.1 & \\
\hline \multirow{2}{*}{$\begin{array}{l}\text { Male gender } \\
\text { no (\%) }\end{array}$} & 1 & 138 & \multicolumn{2}{|c|}{$92(67.7)$} & \multirow{2}{*}{0.05} \\
\hline & 2 & 94 & $83(88$ & & \\
\hline \multirow{2}{*}{$\mathrm{BMI}\left(\mathrm{kg} / \mathrm{m}^{2}\right)$} & 1 & 136 & 27.2 & 4.6 & \multirow{2}{*}{$>0.05$} \\
\hline & 2 & 94 & 26.8 & 4.5 & \\
\hline \multirow{2}{*}{$\begin{array}{l}\text { Left ventricular } \\
\text { EF\% }\end{array}$} & 1 & 129 & 50.5 & 10.7 & \multirow{2}{*}{0.05} \\
\hline & 2 & 94 & 57 & 6.9 & \\
\hline \multirow{2}{*}{ Uric acid } & 1 & 136 & 5.9 & 1.8 & \multirow{2}{*}{0.001} \\
\hline & 2 & 94 & 4.4 & 1.3 & \\
\hline \multirow{2}{*}{ Creatinine } & 1 & 136 & 0.8 & 0.4 & \multirow{2}{*}{$>0.05$} \\
\hline & 2 & 94 & .87 & .11 & \\
\hline \multirow{2}{*}{$\begin{array}{l}\text { Creatinine } \\
\text { clearance }\end{array}$} & 1 & 129 & 73.7 & 60.5 & \multirow{2}{*}{$>0.05$} \\
\hline & 2 & 94 & 73.9 & 15.8 & \\
\hline \multirow{2}{*}{$\begin{array}{l}\mathrm{eGFR}(\mathrm{mL} / \\
\left.\mathrm{min} / 1.73 \mathrm{~m}^{2}\right)\end{array}$} & 1 & 129 & 106.7 & 32.1 & \multirow{2}{*}{0.05} \\
\hline & 2 & 76 & 127.9 & 27.8 & \\
\hline \multirow{2}{*}{$\begin{array}{l}\text { Cystatin-C } \\
\text { (mg/L) }\end{array}$} & 1 & 102 & 1.4 & 1.0 & \multirow{2}{*}{0.05} \\
\hline & 2 & 94 & 0.50 & .26 & \\
\hline \multirow{2}{*}{$\begin{array}{l}\text { Hypertension } \\
\text { no (\%) }\end{array}$} & 1 & 136 & 74 & $(54.4)$ & \multirow{2}{*}{0.05} \\
\hline & 2 & 94 & & & \\
\hline \multirow{2}{*}{$\begin{array}{l}\text { Diabetes no } \\
\text { (\%) }\end{array}$} & 1 & 136 & $60(66$ & & \multirow{2}{*}{0.05} \\
\hline & 2 & 94 & $16(16$ & & \\
\hline
\end{tabular}

eGFR, estimated glomerular filtration rate; EF, ejection fraction. 


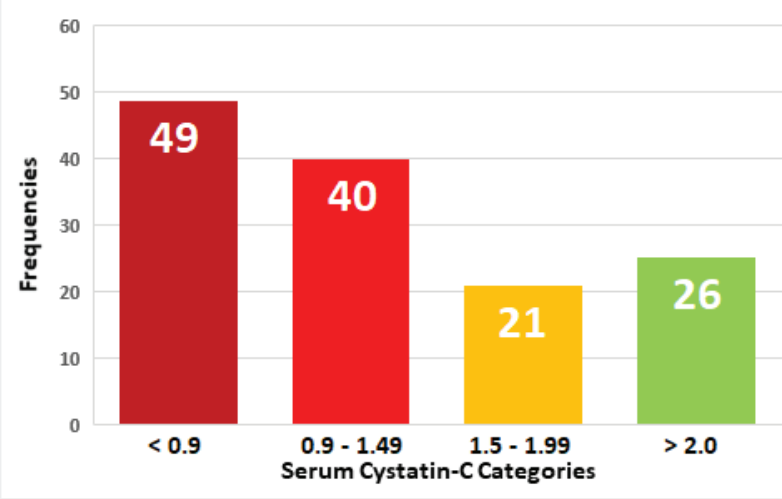

\section{Fig. 1 Frequency of cystatin- $\mathrm{C}(\mathrm{mg} / \mathrm{L})$ quartiles among} ACS patients.

The issue of classification of the subjects' levels of $\mathrm{Cy} / \mathrm{C}$ into quartiles is well-exposed in Fig. 1, which showed that two-thirds of the patients had lower $\mathrm{Cy} / \mathrm{C}$ values than those with higher values.

The distribution of the study variables according to $\mathrm{Cy} / \mathrm{C}$ quartiles is demonstrated well in Table 2. There was no significant variation in the distribution of following variables according to $\mathrm{Cy} / \mathrm{C}$ quartiles: creatinine, $\mathrm{BMI}$, creatinine clearance, UA, eGFR, history of diabetes, hypertension, EF, and angiographic findings regarding the number of stenosed coronaries. Meanwhile, significant difference was observed concerning age, gender, and smoking practice. Linear regression analysis revealed positive weak significant association of $\mathrm{Cy} / \mathrm{C}$ to creatinine, negative and no significant association of $\mathrm{Cy} / \mathrm{C}$ to eGFR and positive significant association of $\mathrm{Cy} / \mathrm{C}$ to SUA in ACS (Figs. 2A-C).

ROC study verified Cy/C 0.955 as a cut-off level to predict incidence of ACS. The sensitivity, specificity, and accuracy for $\mathrm{Cy} / \mathrm{C}$ were 84,86 , and $84 \%$ sequentially, while the sensitivity, specificity, and accuracy of SUA were 58,72 , and $73 \%$ sequentially (Fig. 3). Patients were divided to 2 subgroups: high $\mathrm{Cy} / \mathrm{C}$ group $(\geq 0.95 \mathrm{mg} / \mathrm{L})(\mathrm{n}=61)$ and the low $\mathrm{Cy} / \mathrm{C}(<0.95 \mathrm{mg} / \mathrm{L})$ $(\mathrm{n}=75)$ was the second group.

\section{Discussion}

As a serious disorder, ACS remains a cause of high morbidity and mortality even with considerable therapeutic advances take into consideration risk assessment by using risk factors and risk biomarkers. ${ }^{10}$ On top of out-of-date risk factors, some novel risk issues found to be associated with ACS. ${ }^{11,12}$ Both $^{13,14}$

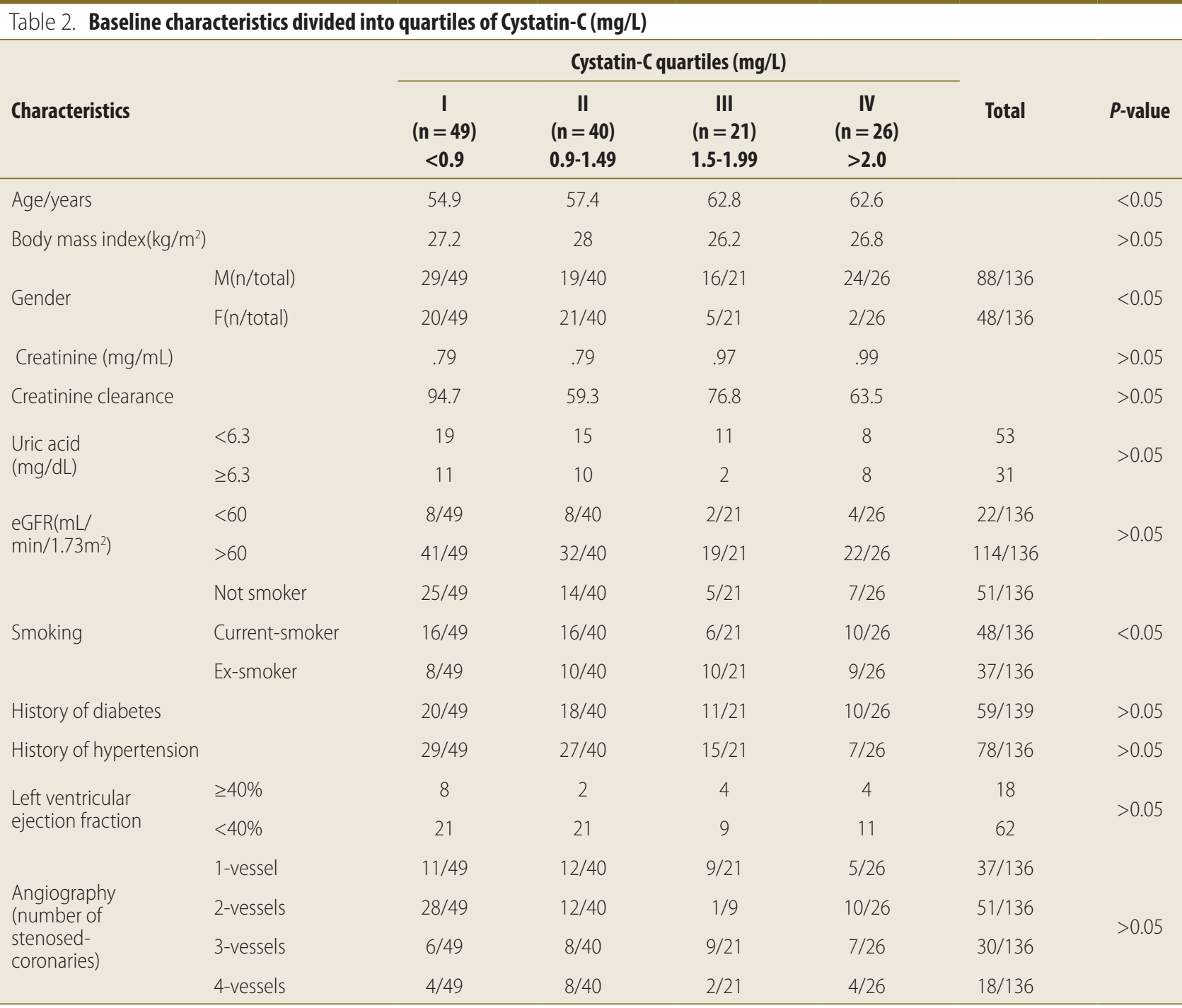



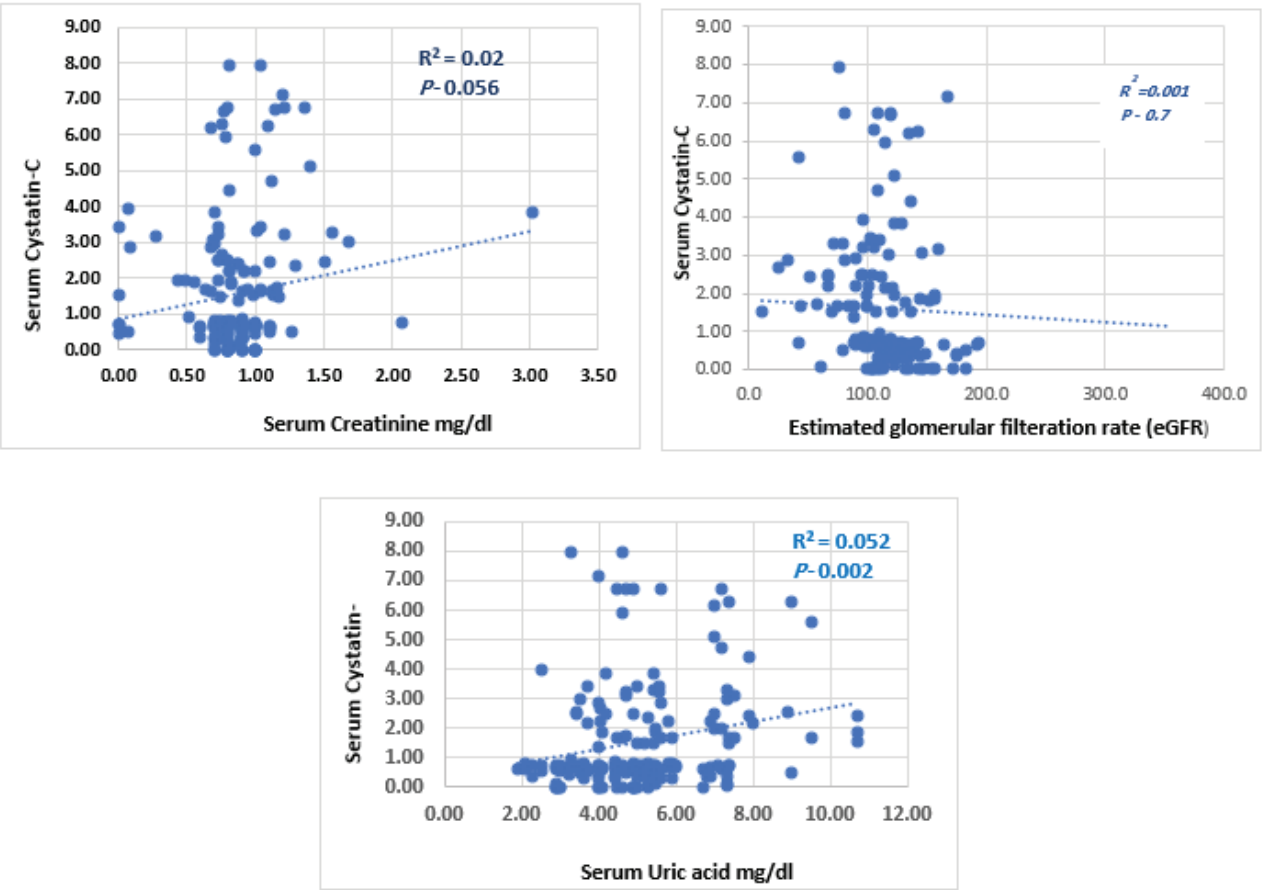

Fig. 2 Scatter blot diagram of cystatin-C to creatinine, estimated glomerular filtration rate, and uric acid in ACS patients.

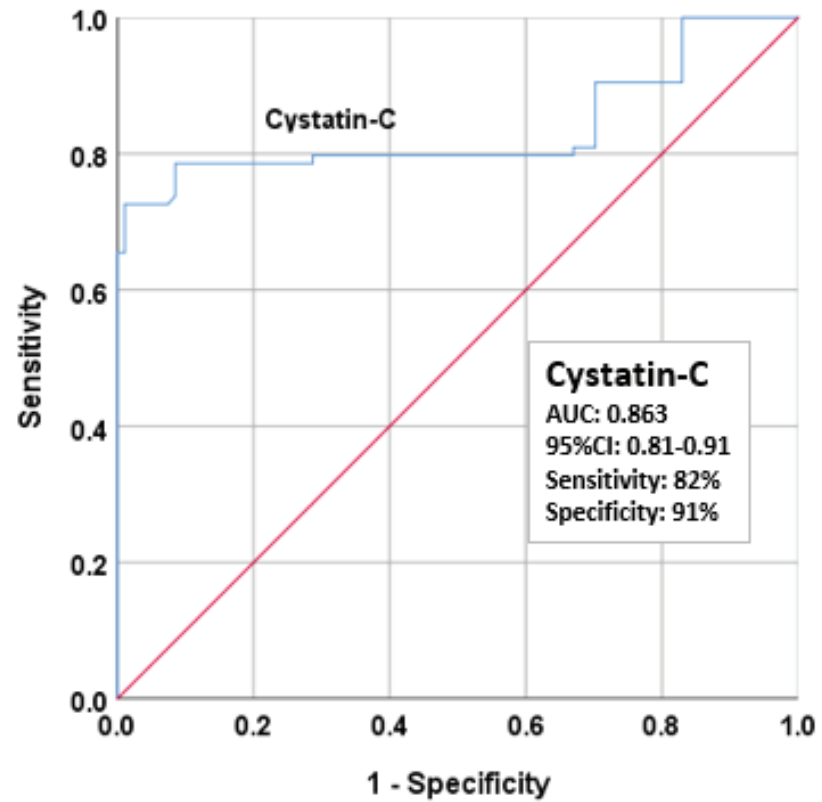

Fig. 3 ROC curve for cystatin-C in acute coronary syndrome.

found that $\mathrm{Cy} / \mathrm{C}$ is less affected by factors like age, sex, and muscular mass over plasma creatinine and therefore might be a good biomarker of cardiovascular risk and cardiac impairment specially during aging. Their findings did not match our study findings of significant variances observed in $\mathrm{Cy} / \mathrm{C}$ quartiles regarding age, sex, and smoking practice. Parikh et al. exposed independent association of high levels of $\mathrm{Cy} / \mathrm{C}$ with risk issues like age, female sex, BMI, and smoking, even in people without chronic kidney diseases. ${ }^{15}$

In this study, $\mathrm{Cy} / \mathrm{C}$ levels in patients and control groups were close to the references of other studies. ${ }^{16,17} \mathrm{Cy} / \mathrm{C}$ was significantly higher in ACS group finding matches with other researches like $\mathrm{Ge}$ et al. ${ }^{18}$ This high level of $\mathrm{Cy} / \mathrm{C}$ could reflect the atherotic changes in ACS subjects as $\mathrm{Cy} / \mathrm{C}$ is expressed in all nucleating cells, controls action of "cysteine proteases." $\mathrm{Cy} / \mathrm{C}$ and its fragments may influence the phagochemotactic ability of neutrophil, shares as well as regulates inflammatory responses. Inflammation contributes a vital role in the progression of atherosis. Thus, $\mathrm{Cy} / \mathrm{C}$ might reflect amplified inflammation which subsidizes to vulnerable coronary-sclerotic plaque. ${ }^{19}$

Our result of a high level of $\mathrm{Cy} / \mathrm{C}$ in ACS patients can document the role of $\mathrm{Cy} / \mathrm{C}$ as a diagnostic biomarker, consistent to other studies like Eriksson et al., ${ }^{20}$ who concluded that $\mathrm{Cy} / \mathrm{C}$ may reflect surely the existence or absence of ACS.

There is overwhelming evidence corroborating the notion that higher $\mathrm{Cy} / \mathrm{C}$ values is correlated to a higher incidence of coronary-vascular events in symptomless elder peoples, and in cardiac failure. Yet, the reasons for such associations are indefinite. ${ }^{21,22}$

Tayeh et al. ${ }^{23}$ assessed prognostic value of $\mathrm{Cy} / \mathrm{C}$ to predict "major adverse cardiac events" in ACS. Therefore, Cy/C might be a valuable biomarker to diagnose coronary sclerosis. Other surveys proposed increased $\mathrm{Cy} / \mathrm{C}$ levels might indicate elevated risk for heart disease/failure, stroke, in addition to mortality. ${ }^{24}$ Meanwhile, close association of $\mathrm{Cy} / \mathrm{C}$ and acute ischemic stroke was also published in another survey. ${ }^{25}$

The positive correlation of $\mathrm{Cy} / \mathrm{C}$ with serum UA and creatinine observed in this work; are consistent with other analyses. ${ }^{12,26}$ Harada et al., ${ }^{26}$ found that $\mathrm{Cy} / \mathrm{C}$ had significant relations with both creatinine and SUA mutually in Japanian undergraduates and this concomitant "high $\mathrm{Cy} / \mathrm{C}$ and SUA values" was related with subclinical lipids dysregulation and proposed the cardiometabolic risks. The negative correlation of $\mathrm{Cy} / \mathrm{C}$ and eGFR in our study is in agreement with Shlipak et $\mathrm{al},{ }^{21}$ who reported higher Cy/C levels which reflect early GFR problems. Further evidences supporting a graded association between high blood Cy/C levels and increased incidence of CVD in people with GFR $\geq 60 \mathrm{~mL} / \mathrm{min} / 1.73 \mathrm{~m}^{2}$. 4,27 
The higher incidence of associated risk factors in term of concomitant hypertension and diabetes mellitus in ACS patients was significant, could be related to the finding of Muntner et $a .^{28}$ who displayed the incidence of risk-factors like tobacco-use, hypertension, besides others was higher in individuals with elevated $\mathrm{Cy} / \mathrm{C}$ concentrations.

Lodh et al., used a cut-off $\mathrm{Cy} / \mathrm{C}$ level of $1 \mathrm{mg} / \mathrm{L}$ and gained sensitivity of 77.8 for distinguishing ACS patients, nevertheless, the specificity was not much 62 and the area under the curve was 0.831 (29). In this study, the cut-off value used was 0.955 , at a higher cut-off we obtained a lesser specificity. The sensitivity was 86 , specificity was 84 and $86 \%$, which indicates the predictive value of $\mathrm{Cy} / \mathrm{C}$ as a biomarker for ACS and this agreed with Qing et al..$^{30}$ findings, who reported a modest predictive rate of $\mathrm{Cy} / \mathrm{C}$ as a single biomarker for ACS.

Our study showed the association of higher $\mathrm{Cy} / \mathrm{C}$ concentration (at the four quartiles) in ACS patients with lower systolic function of the left ventricle reflected by lower EF and this is inconsistent to other analysis like Shuaila et al., who found that higher $\mathrm{Cy} / \mathrm{C}$ values associated with lower $\mathrm{EF}^{31}$ Same outcomes were reported by Moran et al., ${ }^{32}$ who revealed that $\mathrm{Cy} / \mathrm{C}$ can be also a biomarker for cardiac failure. Tayeh et al also showed the association between higher $\mathrm{Cy} / \mathrm{C}$ level and the lower EF. From this finding, we can conclude that $\mathrm{Cy} / \mathrm{C}$ can detect the systolic dysfunction of the $\mathrm{LV}^{23}$

Our data provide a convincing evidence that $\mathrm{Cy} / \mathrm{C}$ level not related to the number of stenosed coronaries. Our finding was in contrast to other studies that showed that the $\mathrm{Cy} / \mathrm{C}$ level have a tendency to increase with increment of diseased coronaries, ${ }^{30,33}$ as well as Tayeh et al, ${ }^{23}$ who found that patients with higher level of Cy/C (cut-off value $1.141 \mathrm{mg} / \mathrm{L}$ ) had a significant high number of stenosed vessels in comparison to patients with lower Cy/C levels. The small sample size might explain these discrepancies. In ACS, the $\mathrm{Cy} / \mathrm{C}$ was not related to the number of coronary arteries affected and this could be due to small size sample.

\section{Conclusion}

$\mathrm{Cy} / \mathrm{C}$ is not only a good marker for early detection of renal impairment, but also could be a valuable biomarker for diagnosing coronary artery diseases, and $\mathrm{Cy} / \mathrm{C}$ in patients with ACS is a powerful predictor of LV systolic dysfunction, assessing severity of the condition, and predict development of heart failure. It seems important to put factors like age, gender, and smoking habits into consideration during evaluation $\mathrm{Cy} / \mathrm{C}$ level as our study showed it is affected by these factors.

\section{Acknowledgments}

We thank the Department of Pharmacology and Toxicology/ College of Pharmacy/University of Babylon. We thank Babylon health directorate/Babel hospital for maternity and childhood, for permission to access the data and the community of Babel thalassemia center for their official support to the study.

\author{
Abbreviations \\ $\mathrm{Cy} / \mathrm{C}$ - Cystatin C \\ ACS - Acute coronary syndrome \\ BMI - body mass index \\ eGFR - Estimated glomerular filtration \\ LVEF - Left ventricular ejection fraction \\ AMI - Acute myocardial infarction \\ SUA - Serum uric acid
}

\section{Conflicts of Interest Disclosure}

There are no conflicts of interest.

\section{Competing Interests}

The authors declare that they have no competing interests.

\section{Source of Funding}

Self-funded project.

\section{Ethics Approval and Consent to Participate}

The Institutional Review Board of the University of Babylon approved this study.

\section{Author Contributions}

All authors confirmed they have contributed to the intellectual content of this paper and have met the following three requirements: (a) significant contributions to the conception and design, acquisition of data, or analysis and interpretation of data; (b) drafting or revising the article for intellectual content, and (c) final approval of the published article. Ammar had an advisory role and a great cooperative effort for sample collection.

\section{References}

1. Deo R, Shlipak MG, Ix JH, Ali S, Schiller NB, Whooley MA. Association of cystatin $C$ with ischemia in patients with coronary heart disease. Clin. Cardiol. 2009;32(11):E18-E22.

2. Huang Q, Shen W, Li J, Luo X, Shi H, Yan P, et al. Association of serum cystatin C levels with acute coronary syndrome in patients of advanced age. J. Int. Med. Res. 2019;47(5):1987-97.

3. Mustafa Begenc Tascanov OY. May cystatin-c be associated with postmyocardial infarction complications? J. Clin. Anal. Med. 2019;10:7.

4. Correa S, Morrow DA, Braunwald E, Davies RY, Goodrich EL, Murphy SA, et al. Cystatin C for risk stratification in patients after an acute coronary syndrome. J. Am. Heart Assoc. 2018;7(20):e009077.

5. Wei L, Ye X, Pei X, Wu J, Zhao W. Reference intervals for serum cystatin $C$ and factors influencing cystatin C levels other than renal function in the elderly. PLoS One. 2014;9(1):e86066-e.

6. Martucheli KFC, Domingueti CP. Clinical usefulness of cystatin C to assess the prognosis of acute coronary syndromes: A systematic review and metaanalysis. Int. J. Cardiovasc. Sci. 2018;31:290-307.

7. Shahbaz H GMUISIISI. Creatinine Clearance. 20192019 Jul 5 [cited Jan 7 2020]. StatPearls Publishing, [cited Jan 7 2020].

8. Levey AS, Bosch JP, Lewis JB, Greene T, Rogers N, Roth D. A more accurate method to estimate glomerular filtration rate from serum creatinine: a new prediction equation. Modification of Diet in Renal Disease Study Group. Ann. Intern. Med. 1999:130(6):461-70. 
9. Mentzer $\mathrm{G}$, Hsich EM. Heart failure with reduced ejection fraction in women: Epidemiology, outcomes, and treatment. Heart Failure Clin. 2019;15(1):19_ 27

10. Amir S Al-Mumim aBMZ, Hayder AA Al-Hindy. Decayed missed filled scores in Iraqi Patients with acute myocardial infarction. Al-Kufa J. Biol. Sci. 2016;8 (3):5.

11. Anderson JL, Adams CD, Antman EM, Bridges CR, Califf RM, Casey DE, Jr., et al. ACC/AHA 2007 guidelines for the management of patients with unstable angina/non-ST-Elevation myocardial infarction: A report of the American College of Cardiology/American Heart Association Task Force on Practice Guidelines (Writing Committee to Revise the 2002 Guidelines for the Management of Patients With Unstable Angina/NonST-Elevation Myocardial Infarction) developed in collaboration with the American College of Emergency Physicians, the Society for Cardiovascular Angiography and Interventions, and the Society of Thoracic Surgeons endorsed by the American Association of Cardiovascular and Pulmonary Rehabilitation and the Society for Academic Emergency Medicine. J. Am. Coll. Cardiol. 2007:50(7):e1-e157.

12. Lodh M, Goswami B, Parida A, Patra S, Saxena A. Assessment of serum leptin, pregnancy-associated plasma protein A and CRP levels as indicators of plaque vulnerability in patients with acute coronary syndrome. Cardiovasc. J. Afr. 2012;23(6):330-5.

13. Nagesh CM, Roy A. Role of biomarkers in risk stratification of acute coronary syndrome. Ind. J. Med. Res. 2010;132:627-33.

14. Sarnak MJ, Katz R, Stehman-Breen CO, Fried LF, Jenny NS, Psaty BM, et al. Cystatin $C$ concentration as a risk factor for heart failure in older adults. Ann. Intern. Med. 2005;142(7):497-505.

15. Parikh NI, Hwang SJ, Yang Q, Larson MG, Guo CY, Robins SJ, et al. Clinical correlates and heritability of cystatin C (from the Framingham Offspring Study). Am. J. Cardiol. 2008;102(9):1194-8.

16. Kyhse-Andersen J, Schmidt C, Nordin G, Andersson B, Nilsson-Ehle P, Lindstrom $V$, et al. Serum cystatin C, determined by a rapid, automated particle-enhanced turbidimetric method, is a better marker than serum creatinine for glomerular filtration rate. Clin. Chem. 1994;40(10):1921-6.

17. Norlund L, Fex G, Lanke J, Von Schenck H, Nilsson JE, Leksell H, et al. Reference intervals for the glomerular filtration rate and cell-proliferation markers: serum cystatin C and serum beta 2-microglobulin/cystatin C-ratio. Scandinav. J. Clin. Lab. Investig. 1997:57(6):463-70.

18. Ge C, Ren F, Lu S, Ji F, Chen X, Wu X. Clinical prognostic significance of plasma cystatin $C$ levels among patients with acute coronary syndrome. Clin. Cardiol. 2009;32(11):644-8.

19. Bharat Lochan KBR. Cystatin-C as a potential risk factor for acute myocardial infarction with normal renal function. Int. Arch. Integr. Med. 2019;6(1):7.
20. Eriksson P, Jones KG, Brown LC, Greenhalgh RM, Hamsten A, Powell JT. Genetic approach to the role of cysteine proteases in the expansion of abdominal aortic aneurysms. Br. J. Surg. 2004;91(1):86-9.

21. Shlipak MG, Katz R, Sarnak MJ, Fried LF, Newman AB, Stehman-Breen C, et al. Cystatin $C$ and prognosis for cardiovascular and kidney outcomes in elderly persons without chronic kidney disease. Ann. Intern. Med. 2006;145(4):23746.

22. Keller T, Messow CM, Lubos E, NicaudV, Wild PS, Rupprecht HJ, et al. Cystatin $\mathrm{C}$ and cardiovascular mortality in patients with coronary artery disease and normal or mildly reduced kidney function: Results from the AtheroGene study. Eur. Heart J. 2009:30(3):314-20.

23. Tayeh O, Rizk A, Mowafy A, Salah S, Gabr K. Cystatin-C as a predictor for major adverse cardiac events in patients with acute coronary syndrome. Egypt. Heart J. 2012;64(3):87-95.

24. Shlipak MG, Matsushita K, Arnlov J, Inker LA, Katz R, Polkinghorne KR, et al. Cystatin $C$ versus creatinine in determining risk based on kidney function. New Engl. J. Med. 2013;369(10):932-43.

25. Huang GX, Ji XM, Ding YC, Huang HY. Association between serum cystatin $C$ levels and the severity or potential risk factors of acute ischemic stroke. Neurol. Res. 2016;38(6):518-23

26. Harada M, Izawa A, Hidaka H, Nakanishi K, Terasawa F, Motoki H, et al. Importance of cystatin C and uric acid levels in the association of cardiometabolic risk factors in Japanese junior high school students. J. Cardiol. 2017;69(1):222-7.

27. Latta F, de Filippi C. Role for cystatin C-based risk stratification for patients after acute coronary syndrome in the era of high sensitivity cardiac troponin assays. J. Am. Heart Assoc. 2018:7(20):e010589-e.

28. Muntner P, Mann D, Winston J, Bansilal S, Farkouh ME. Serum cystatin C and increased coronary heart disease prevalence in US adults without chronic kidney disease. Am. J. Cardiol. 2008;102(1):54-7.

29. Lodh M, Parida A, Sanyal J, Ganguly A. Cystatin C in acute coronary syndrome. Ejifcc. 2013;24(2):61-7.

30. Qing X, Furong W, Yunxia L, Jian Z, Xuping W, Ling G. Cystatin C and asymptomatic coronary artery disease in patients with metabolic syndrome and normal glomerular filtration rate. Cardiovasc. Diabetol. 2012;11:108.

31. Shuaila M, Abdulamir, Hassanain, Alshok, Monem. Prognostic value of cystatin C in acute coronary syndrome. J. Contemp. Med. Sci. 2016;2(4):4.

32. Moran A, Katz R, Smith NL, Fried LF, Sarnak MJ, Seliger SL, et al. Cystatin C concentration as a predictor of systolic and diastolic heart failure. J. Cardiac Failure. 2008;14(1):19-26.

33. Sekizuka H, Akashi YJ, Kawasaki K, Yamauchi M, Musha H. Cystatin C: A better marker to detect coronary artery sclerosis. J. Cardiol. 2009;54(3):35967.

This work is licensed under a Creative Commons Attribution-NonCommercial 3.0 Unported License which allows users to read, copy, distribute and make derivative works for non-commercial purposes from the material, as long as the author of the original work is cited properly. 